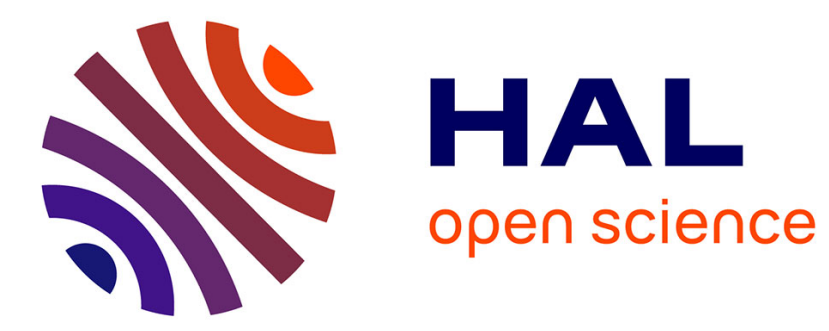

\title{
Manganese toxicity in tomato plants: effects on cation uptake and distribution
}

\author{
Jacques Le Bot, E.A. Kirkby, M.L. van Beusichem
}

\section{To cite this version:}

Jacques Le Bot, E.A. Kirkby, M.L. van Beusichem. Manganese toxicity in tomato plants: effects on cation uptake and distribution. Journal of Plant Nutrition, 1990, 13 (5), pp.513-525. hal-02713364

\section{HAL Id: hal-02713364 \\ https://hal.inrae.fr/hal-02713364}

Submitted on 1 Jun 2020

HAL is a multi-disciplinary open access archive for the deposit and dissemination of scientific research documents, whether they are published or not. The documents may come from teaching and research institutions in France or abroad, or from public or private research centers.
L'archive ouverte pluridisciplinaire HAL, est destinée au dépôt et à la diffusion de documents scientifiques de niveau recherche, publiés ou non, émanant des établissements d'enseignement et de recherche français ou étrangers, des laboratoires publics ou privés. 

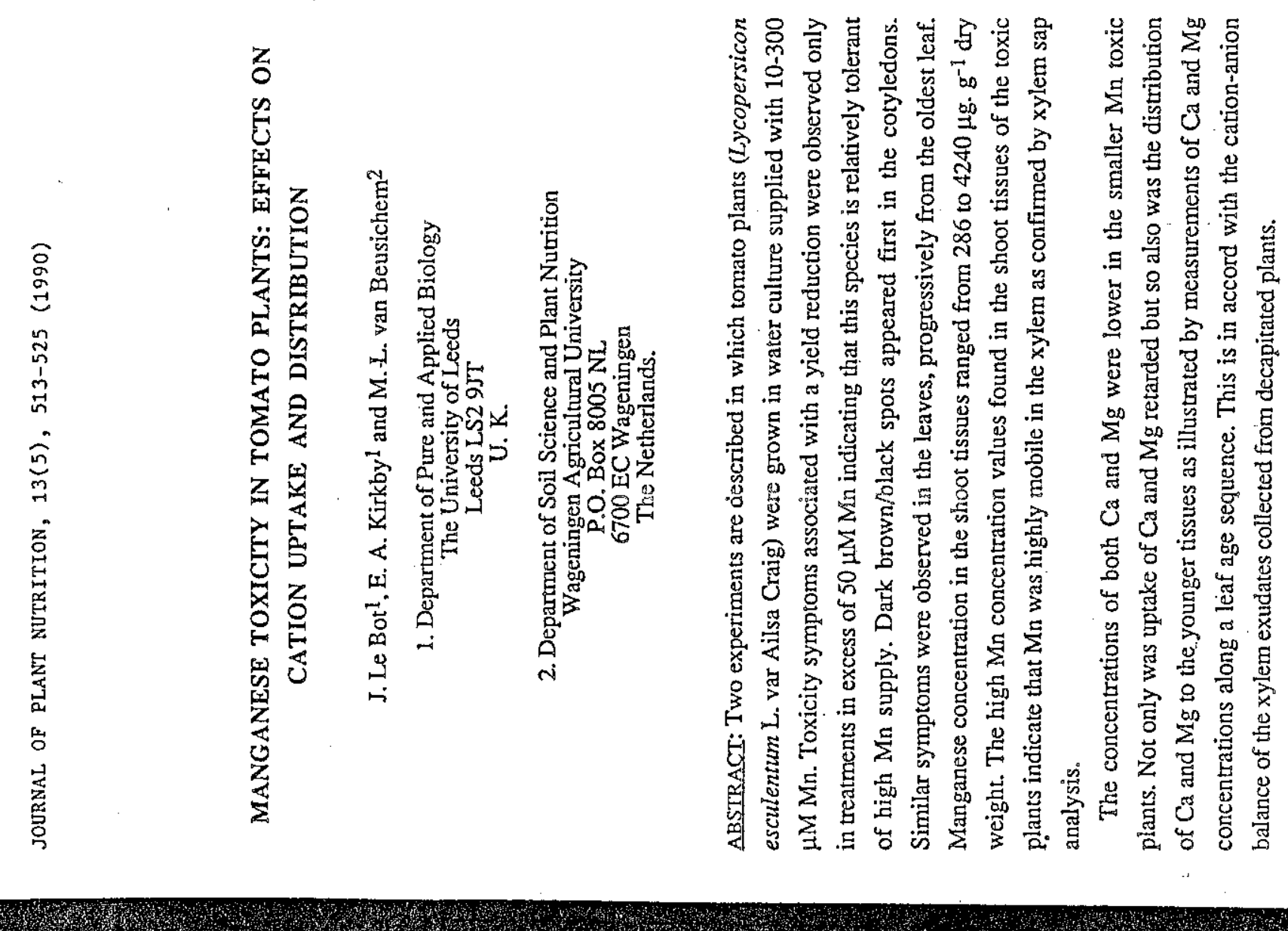

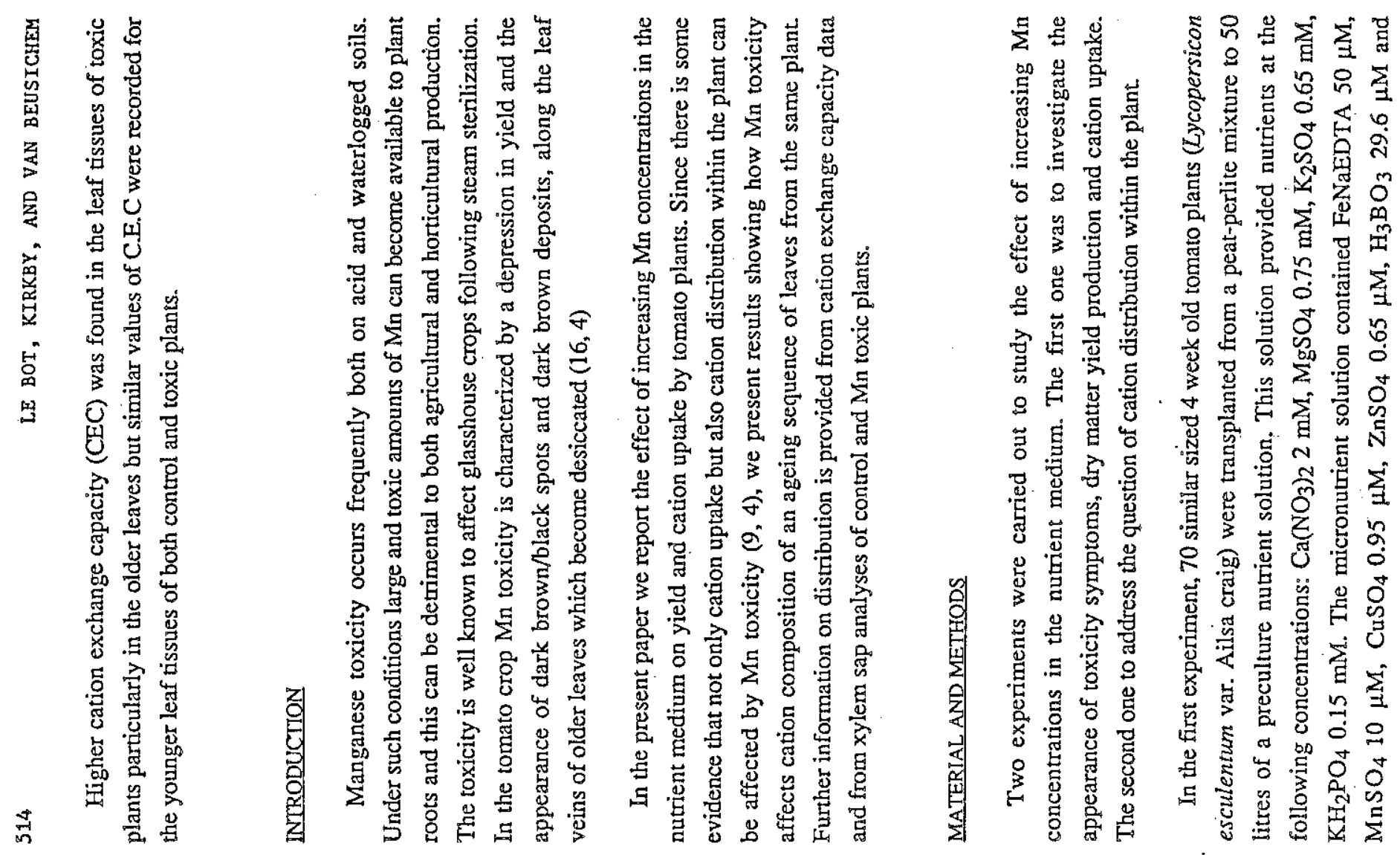


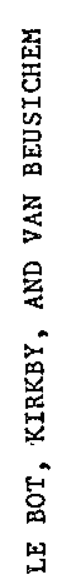

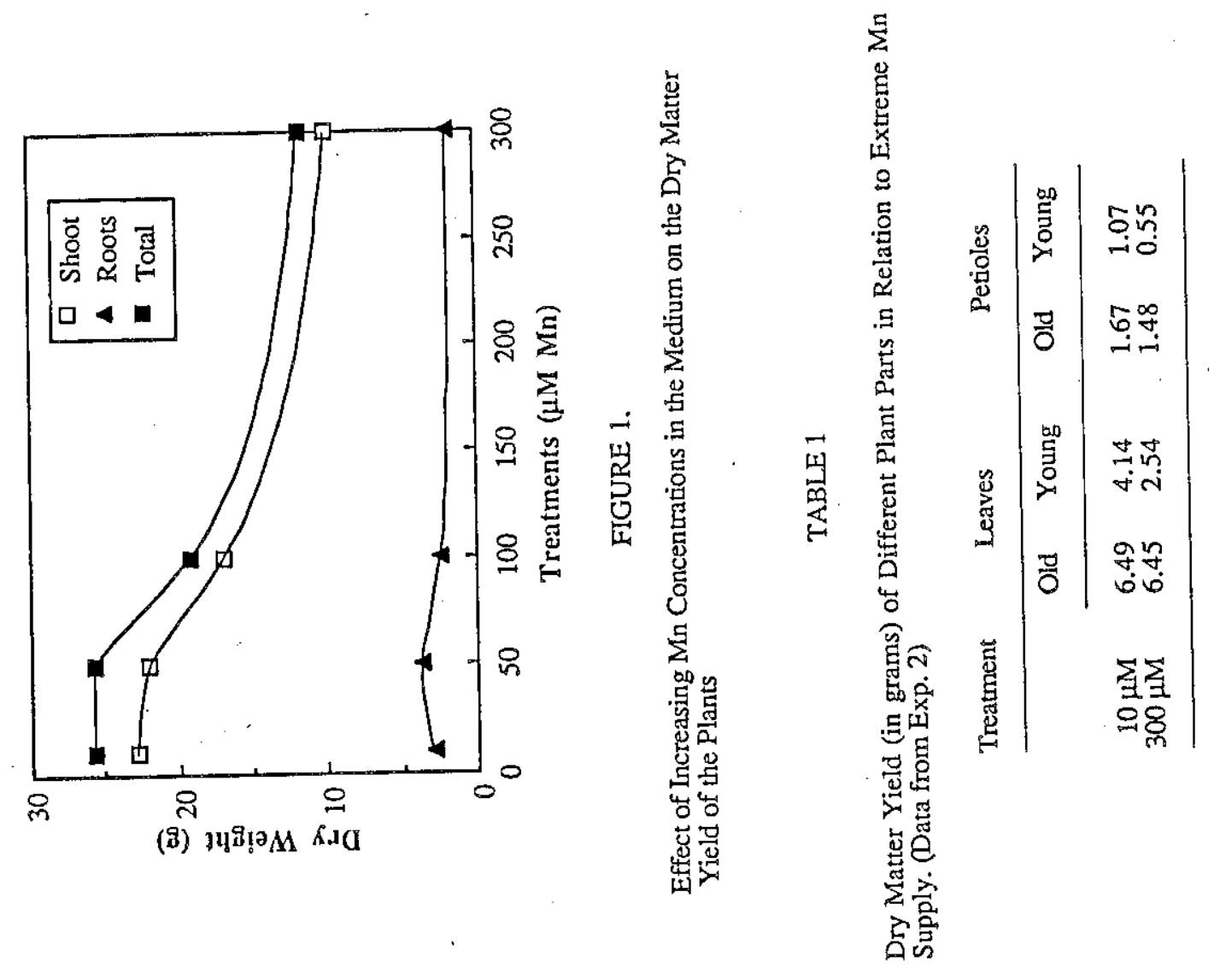

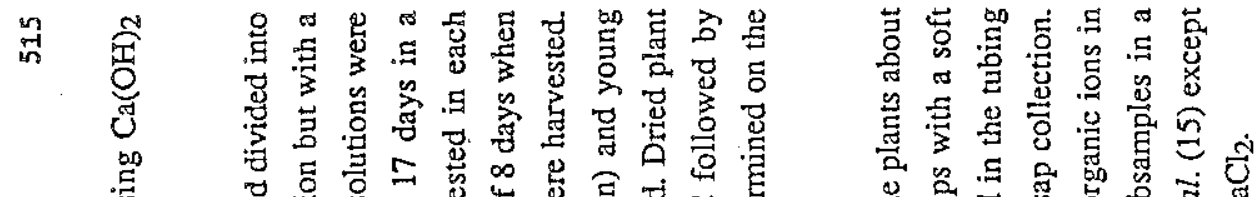

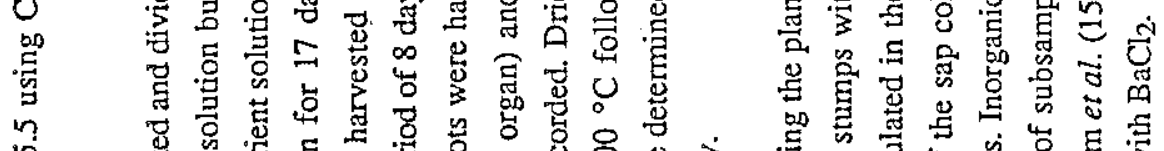

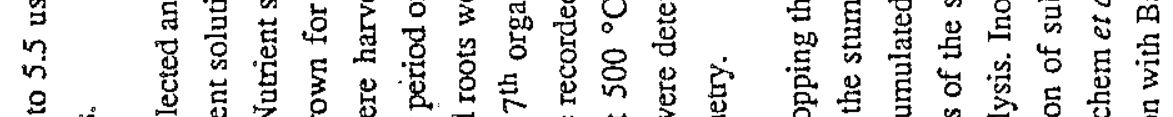

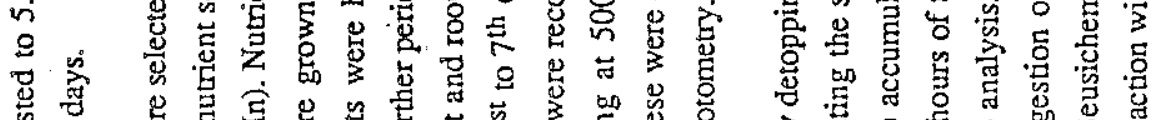

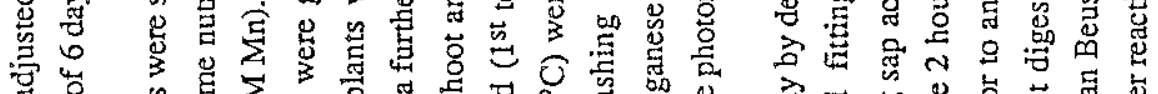

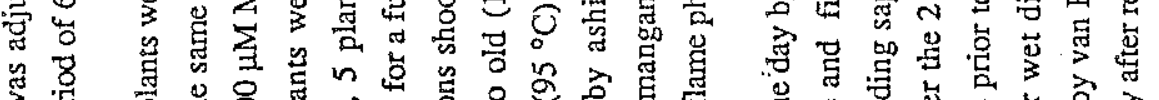

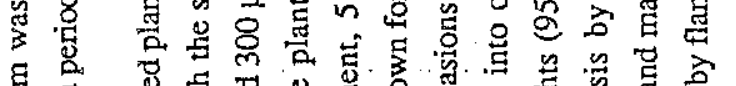

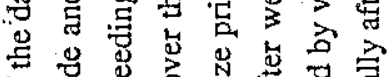

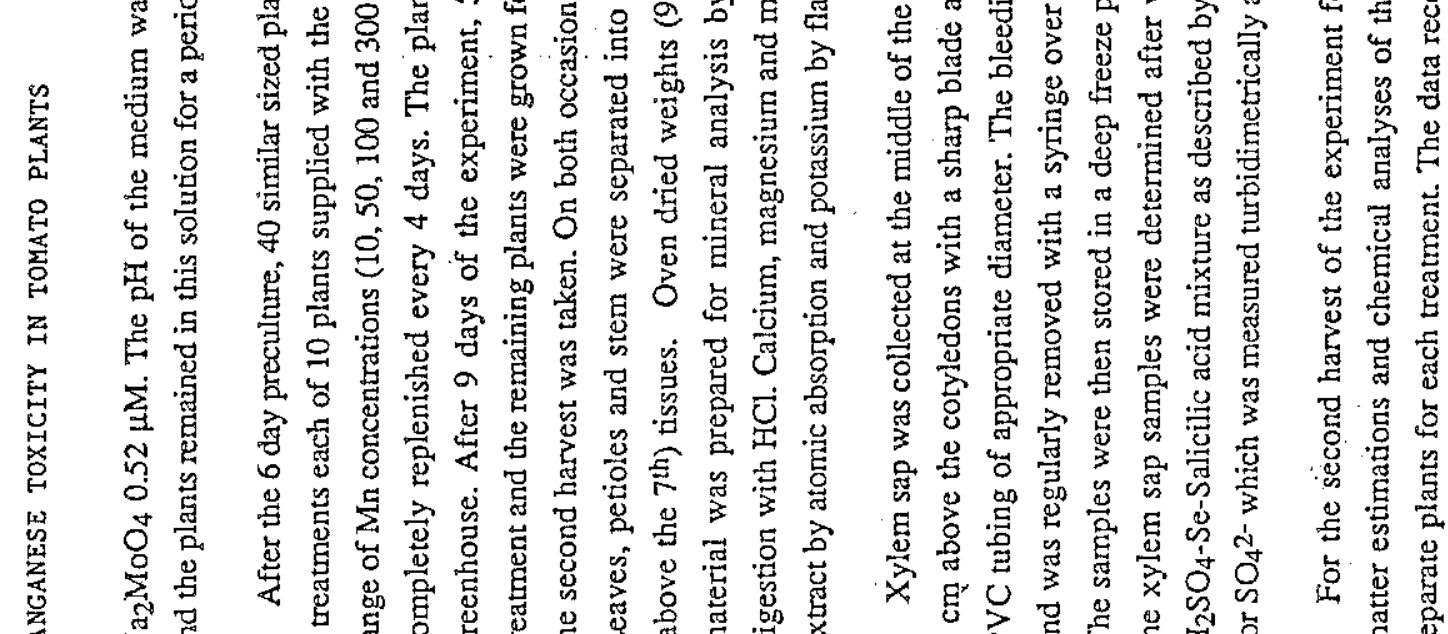
$\stackrel{\leftrightarrow}{\mathrm{B}}$

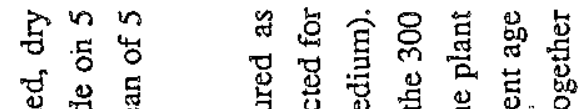

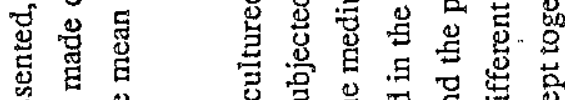

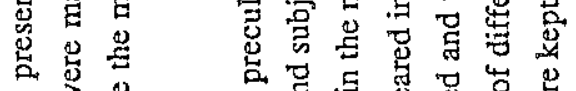
壱造 奇营总 氖

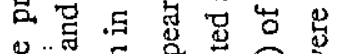

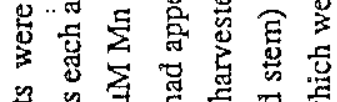

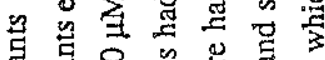

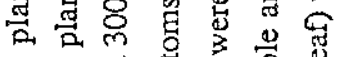

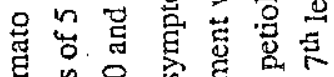

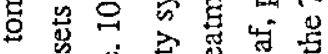

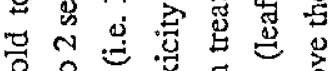

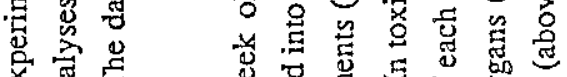

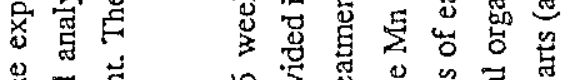

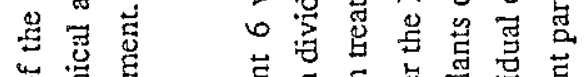

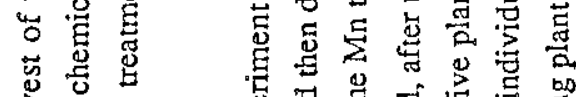

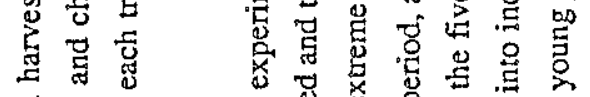

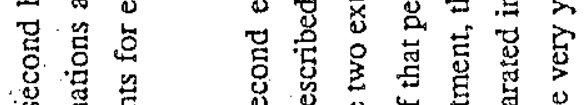

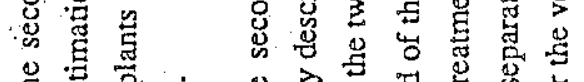

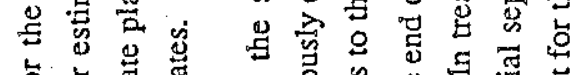

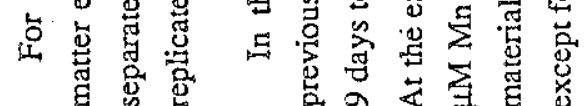



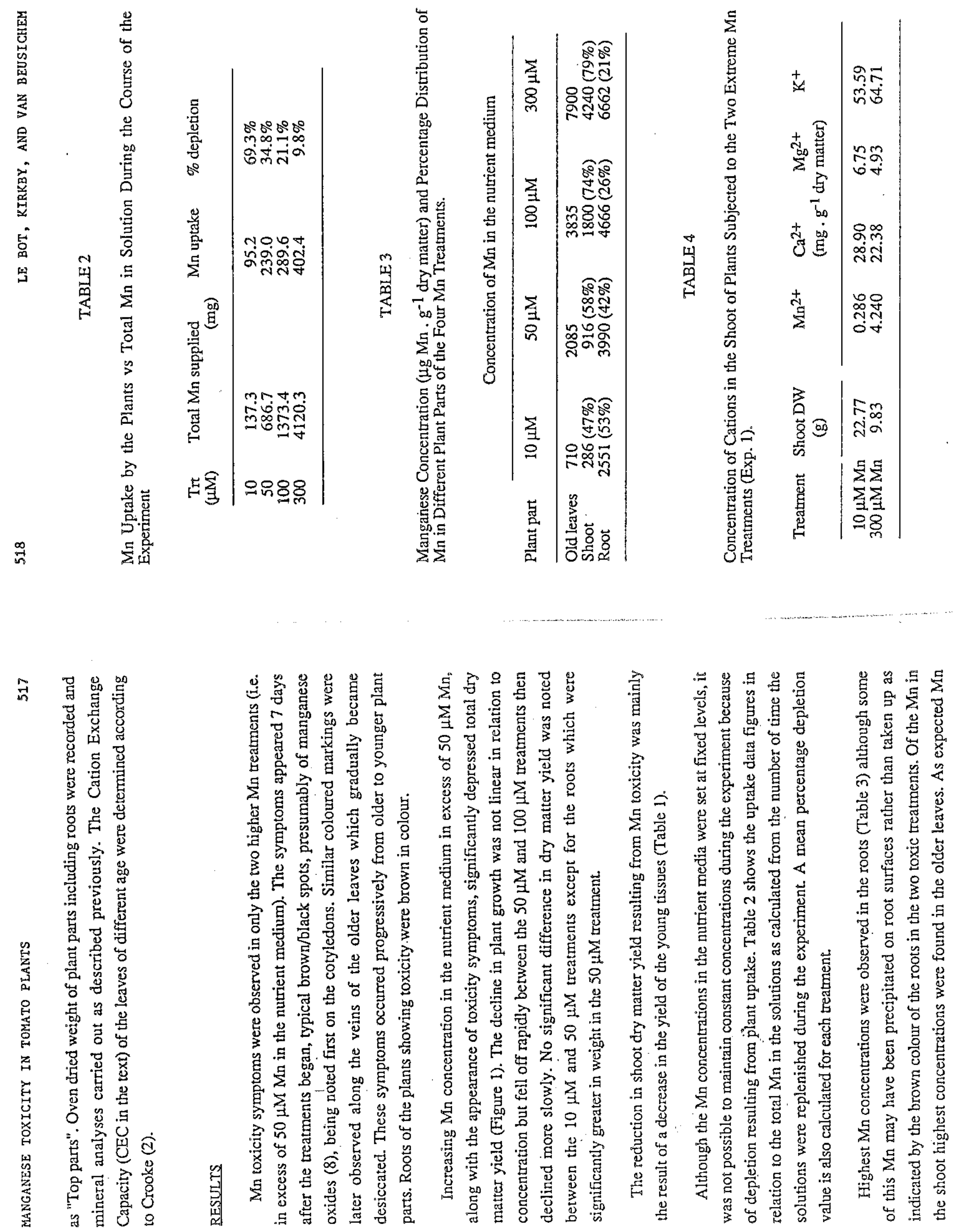


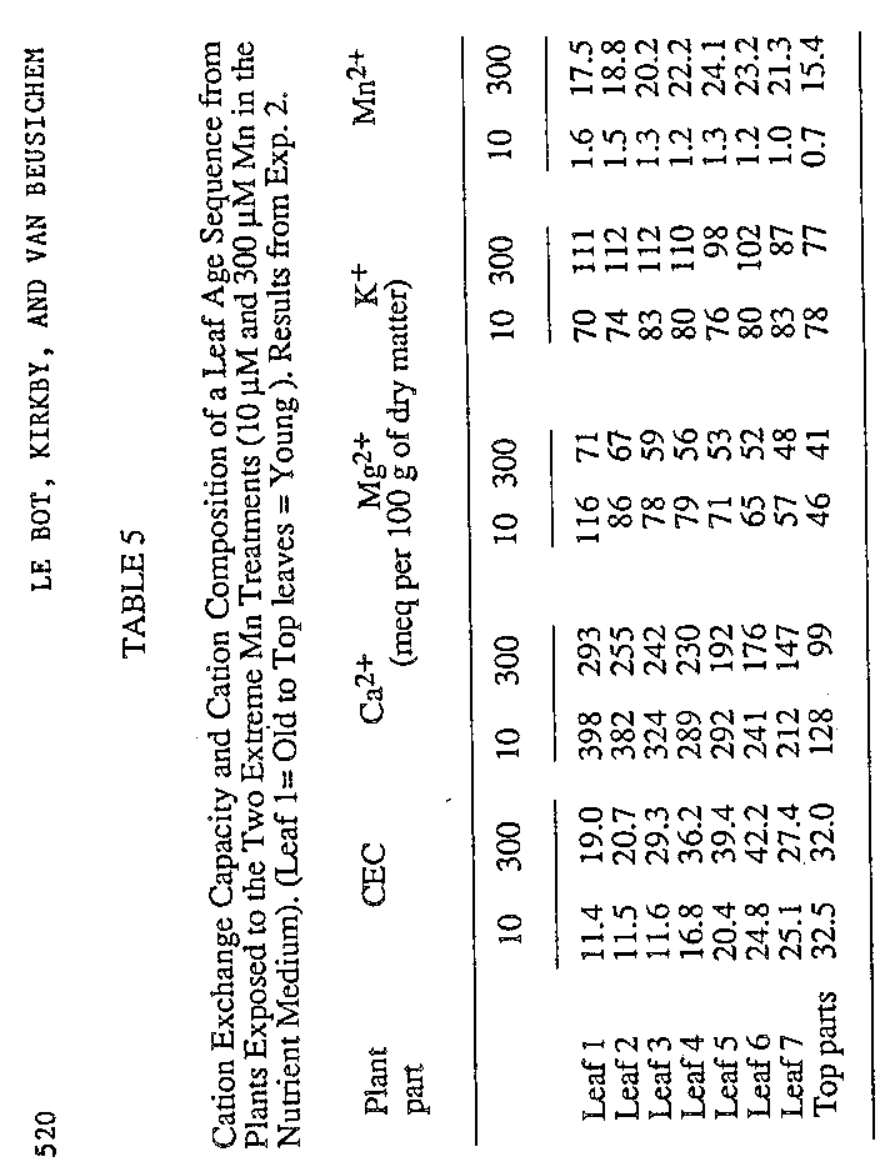

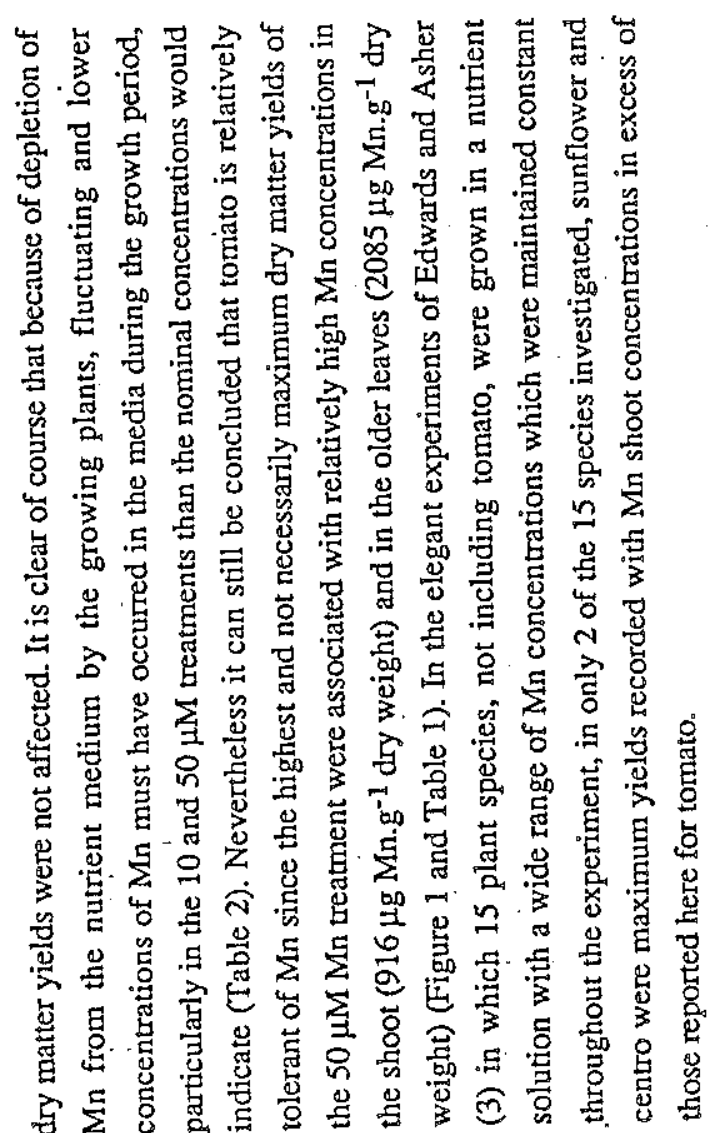

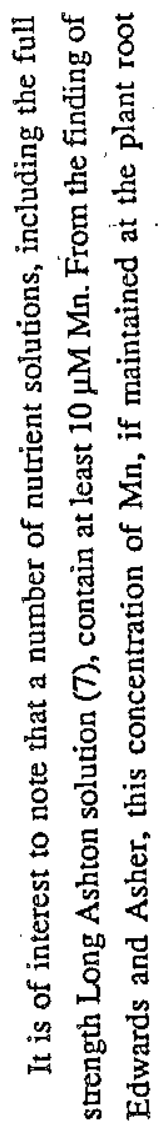

总吢

点

\& 0

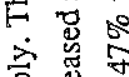

穿总

志点

$\sum$

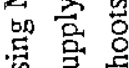

氙 焉

点豆

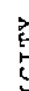

今.

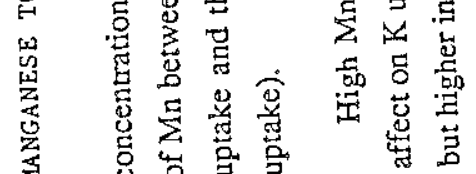

总 氙

蛋

可

茞

苛

कo

穿

\%

岁蒙

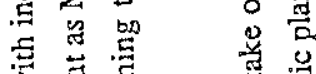

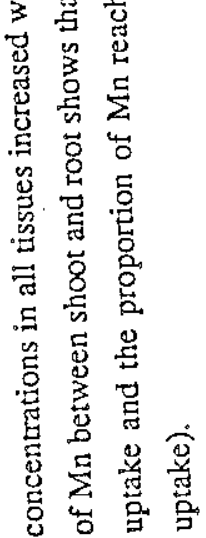

范 号点

वृ

岕 营

营 总

总递

突证

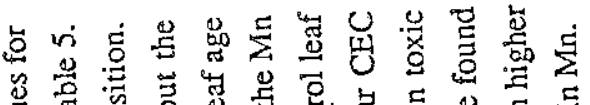

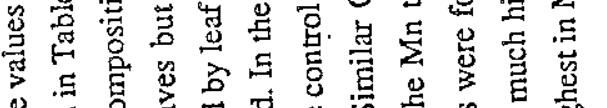

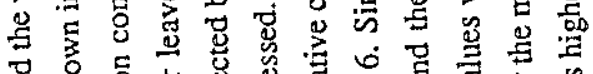

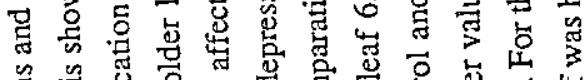

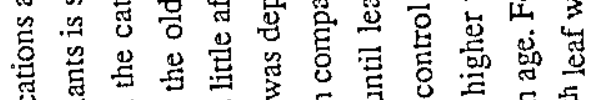
矛至. 至过空

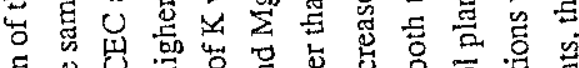

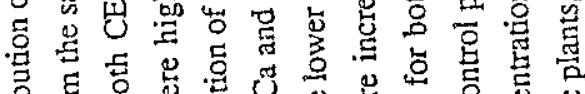

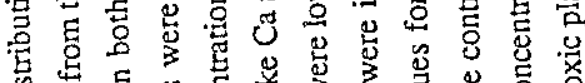

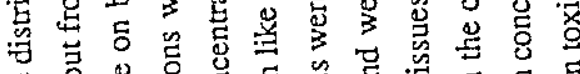
号号记

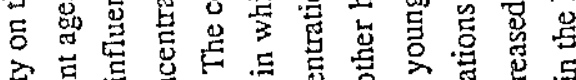

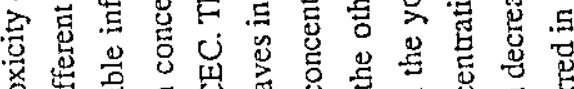

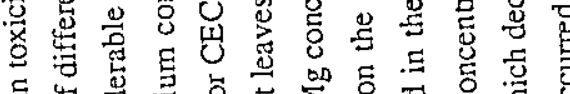

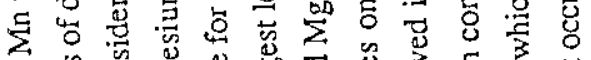

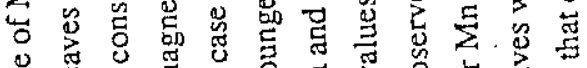

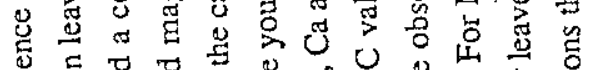

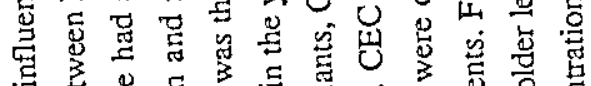

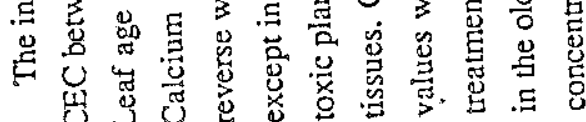

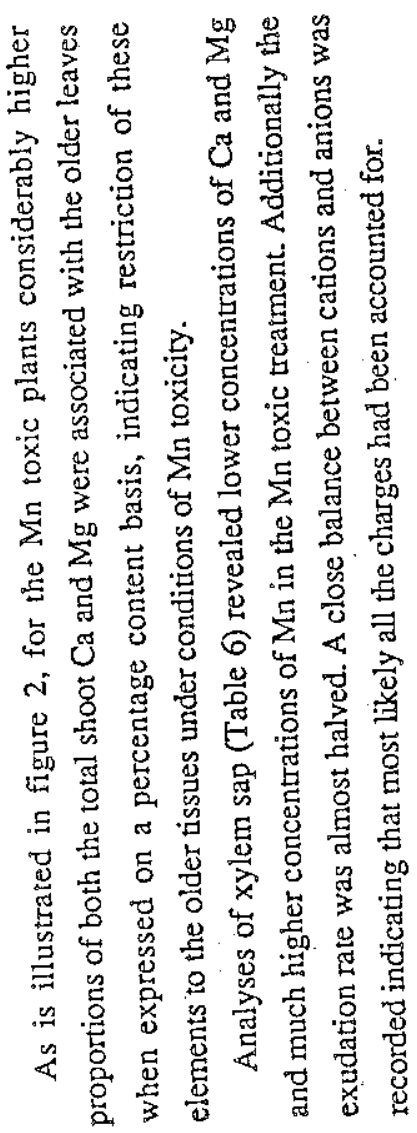

క.

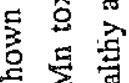
岁出

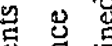

莺 $\stackrel{\leftrightarrow}{\circ} \stackrel{\circ}{\circ}$ 要远 $\sum_{5} 8$ 㤐 号 을 氙 . 运焉 突氞 苋公专 氖 吾 总宫言 苔 导 政 羿 䓌出 


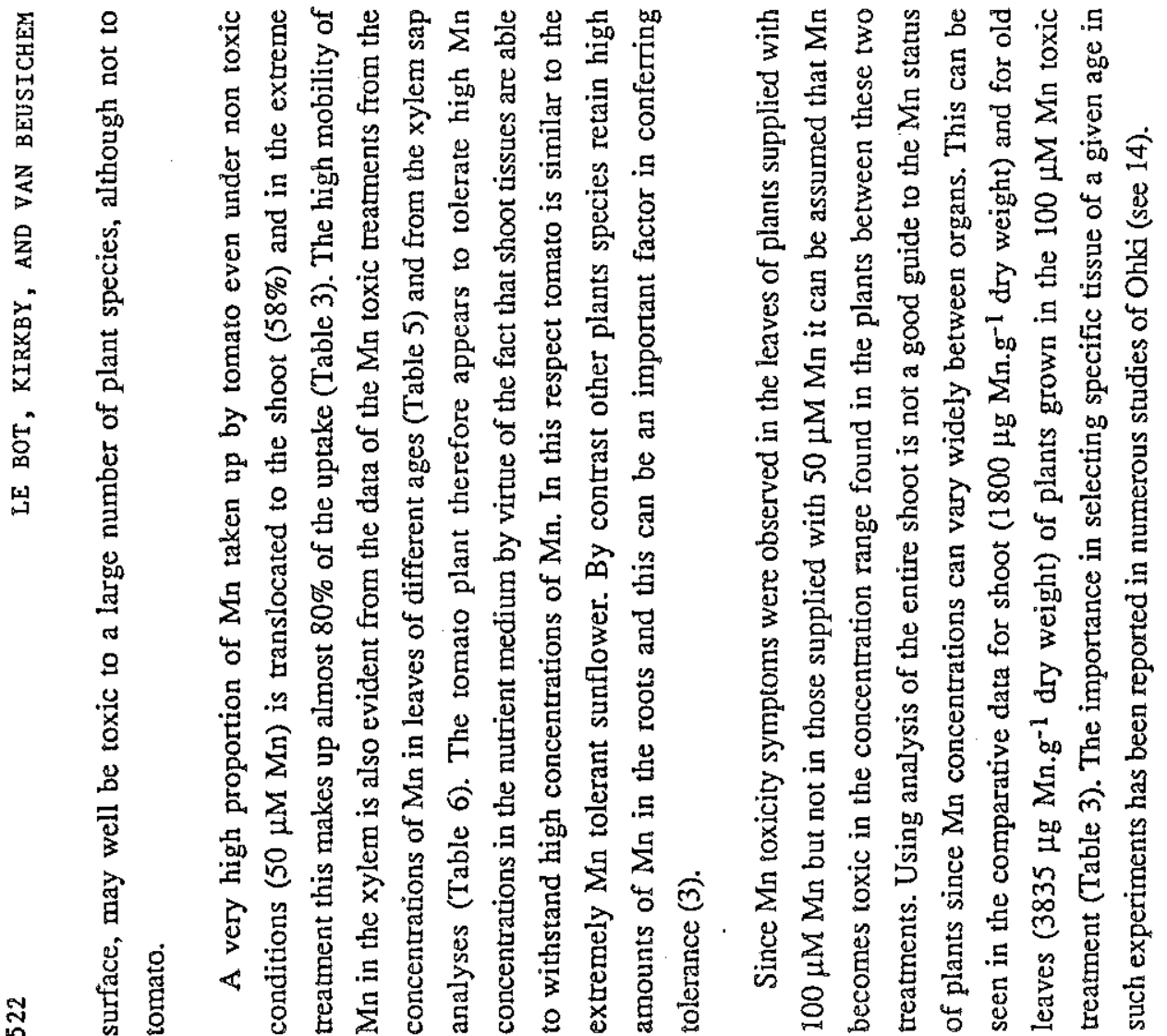

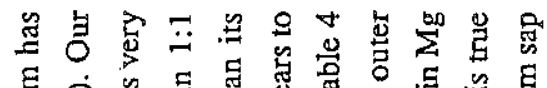

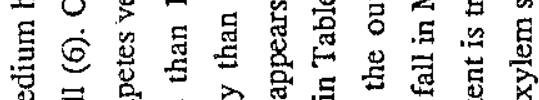

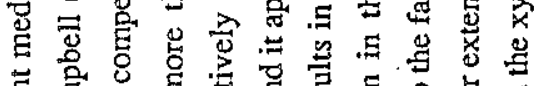

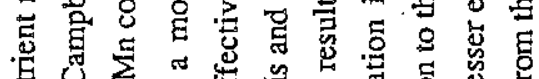

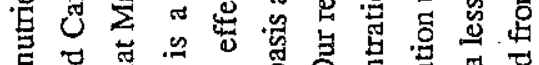

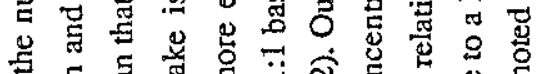

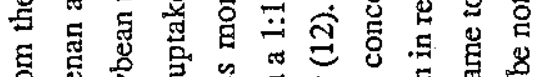

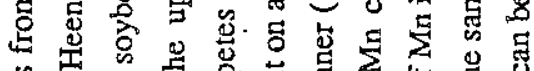

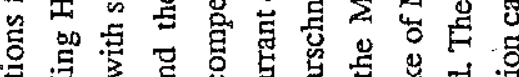

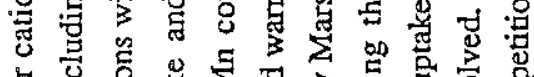

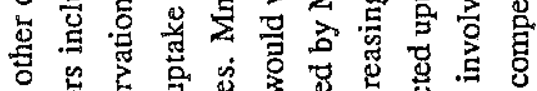

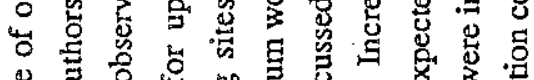
牙

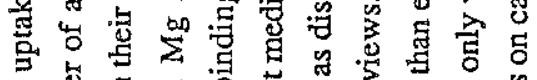

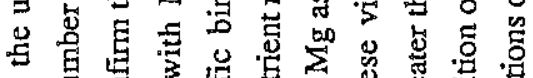

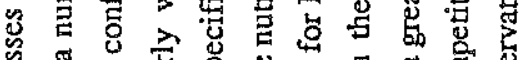

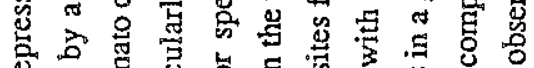

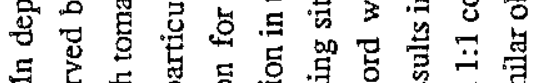

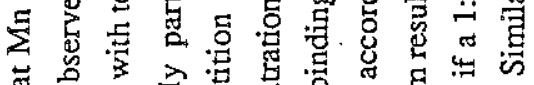

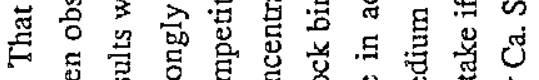

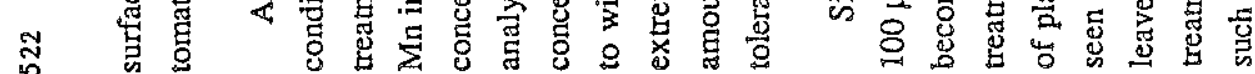
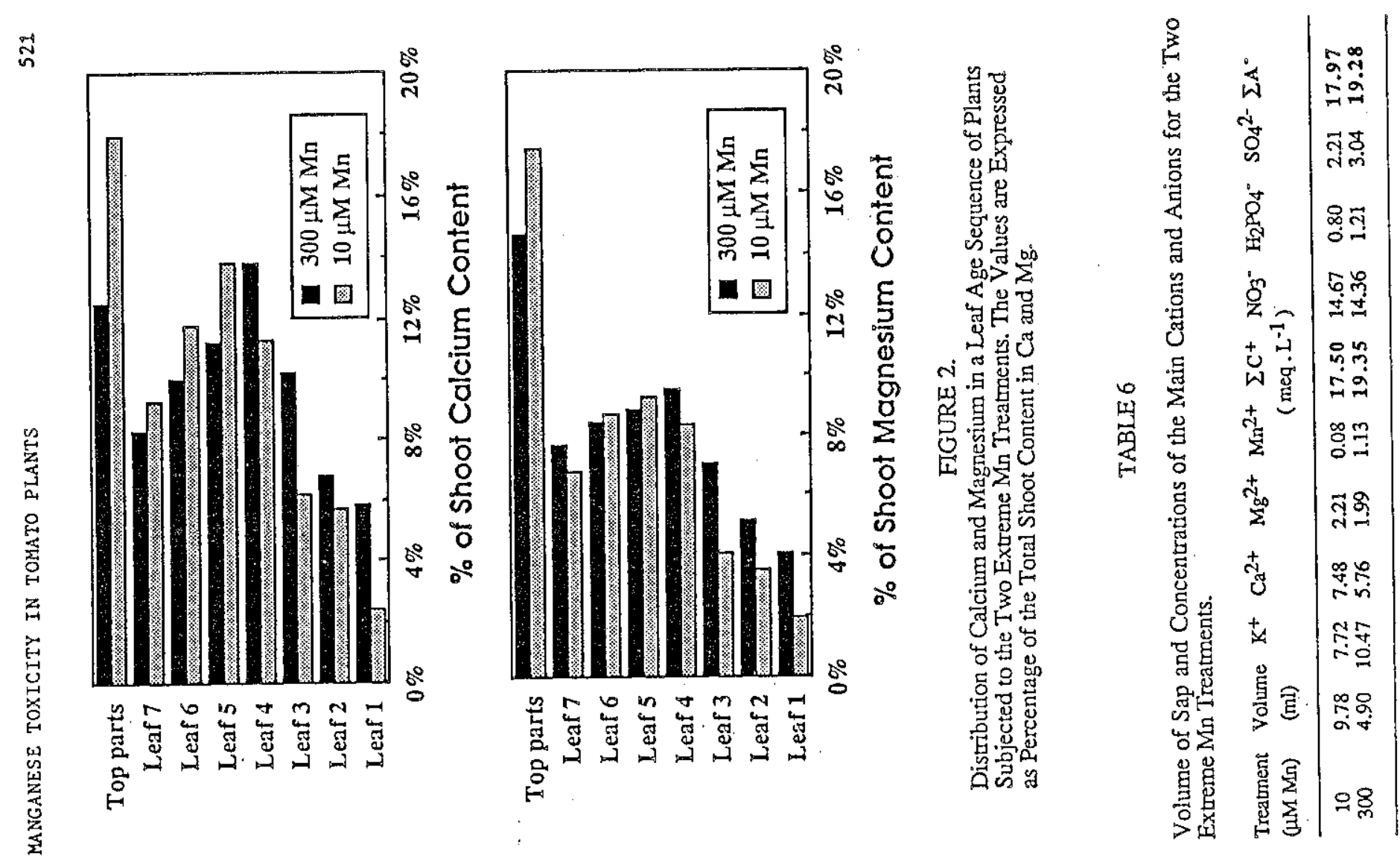

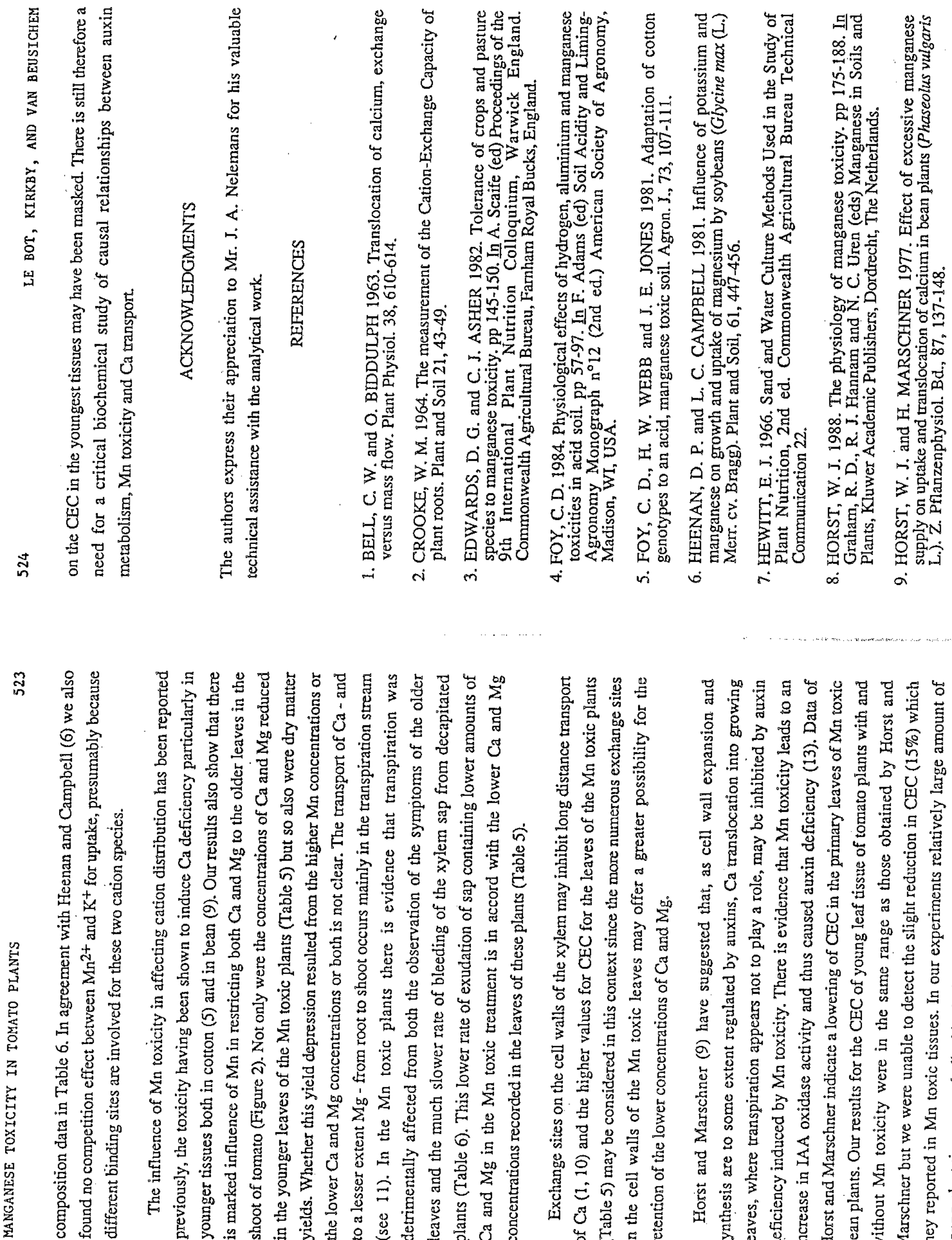

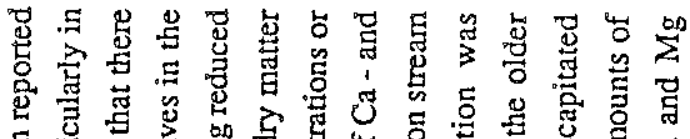

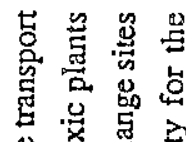

这总语

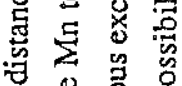

of

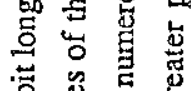

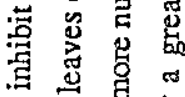

害嵒点

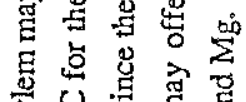

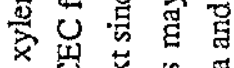

论

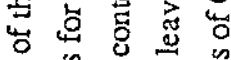

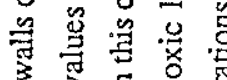

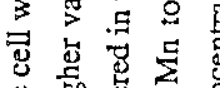
垔啳

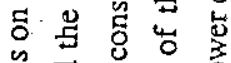

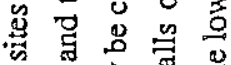

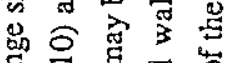

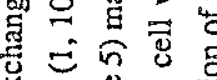

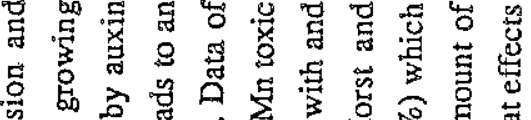

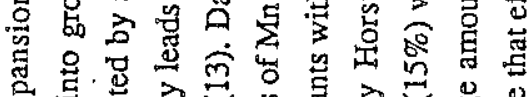

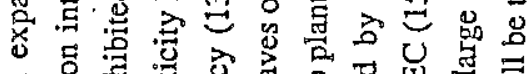

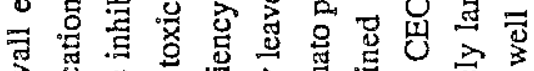

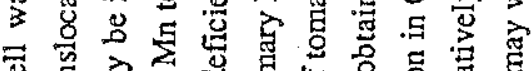

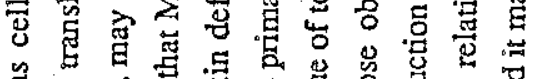

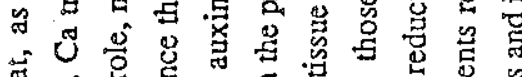

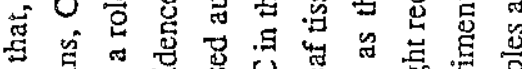

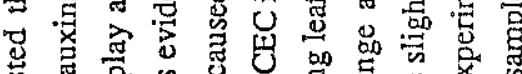

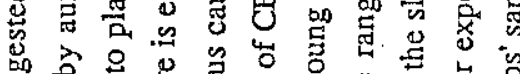

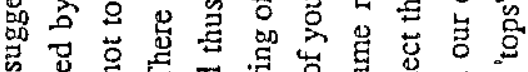

\%

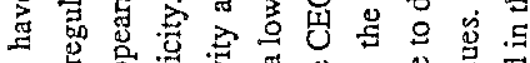

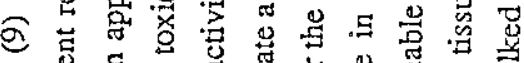

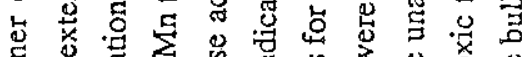

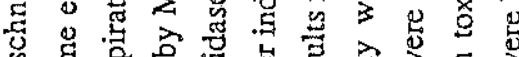

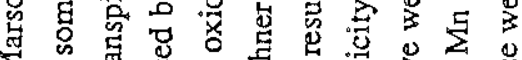

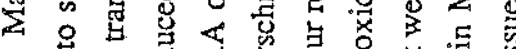

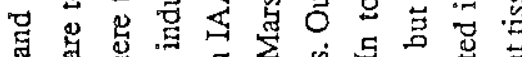

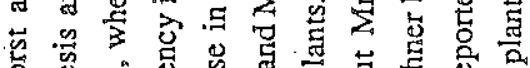

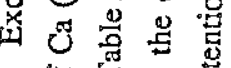

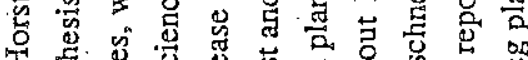

岁 


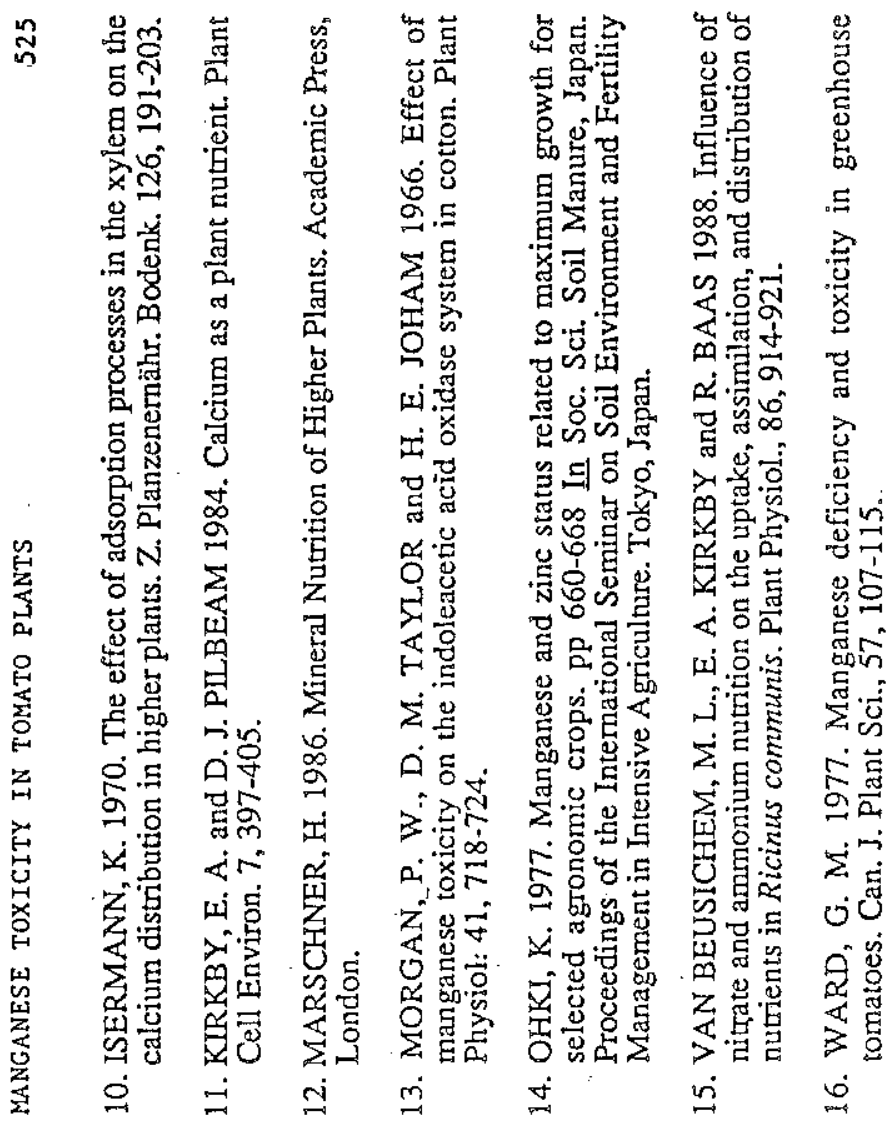

